\title{
Influence of chronic hyperglycemia on the loss of the unfolded protein response in transplanted islets
}

\author{
Stacey N Walters ${ }^{1}$, Jude Luzuriaga', Jeng Yie Chan', Shane T Grey ${ }^{1,2}$ \\ and D Ross Laybutt ${ }^{1,2}$ \\ ${ }^{1}$ Garvan Institute of Medical Research, 384 Victoria Street, Darlinghurst, Sydney, New South Wales 2010, Australia \\ ${ }^{2}$ St Vincent's Clinical School, University of New South Wales, Sydney, New South Wales, Australia
}

Correspondence should be addressed to D R Laybutt or S T Grey Emails r.laybutt@garvan.org.au or s.grey@garvan.org.au

\begin{abstract}
Chronic hyperglycemia contributes to $\beta$-cell dysfunction in diabetes and with islet transplantation, but the mechanisms remain unclear. Recent studies demonstrate that the unfolded protein response (UPR) is critical for $\beta$-cell function. Here, we assessed the influence of hyperglycemia on UPR gene expression in transplanted islets. Streptozotocin-induced diabetic or control nondiabetic mice were transplanted under the kidney capsule with syngeneic islets either sufficient or not to normalize hyperglycemia. Twenty-one days after transplantation, islet grafts were excised and RT-PCR was used to assess gene expression. In islet grafts from diabetic mice, expression levels of many UPR genes of the IRE1/ATF6 pathways, which are important for adaptation to endoplasmic reticulum stress, were markedly reduced compared with that in islet grafts from control mice. UPR genes of the PERK pathway were also downregulated. The normalization of glycemia restored the changes in mRNA expression, suggesting that chronic hyperglycemia contributes to the downregulation of multiple arms of UPR gene expression. Similar correlations were observed between blood glucose and mRNA levels of transcription factors involved in the maintenance of $\beta$-cell phenotype and genes implicated in $\beta$-cell function, suggesting convergent regulation of UPR gene expression and $\beta$-cell differentiation by hyperglycemia. However, the normalization of glycemia was not accompanied by restoration of antioxidant or pro-inflammatory cytokine mRNA levels, which were increased in islet grafts from diabetic mice. These studies demonstrate that chronic hyperglycemia contributes to the downregulation of multiple arms of UPR gene expression in transplanted mouse islets. Failure of the adaptive UPR may contribute to $\beta$-cell dedifferentiation and dysfunction in diabetes.
\end{abstract}

\author{
Key Words \\ - diabetes \\ - endoplasmic reticulum stress \\ - glucotoxicity \\ - islet transplantation \\ - unfolded protein response
}

Journal of Molecular Endocrinology (2013) 51, 225-232

\section{Introduction}

The deleterious effects of chronic hyperglycemia on pancreatic $\beta$-cells, a concept termed as glucotoxicity, have been implicated in the alterations in functional $\beta$-cell mass in diabetes and with islet transplantation (Korsgren et al. 1990, Ogawa et al. 1995, Laybutt et al. 2007a, Poitout \& Robertson 2008, Weir et al. 2009, Bensellam et al. 2012). Much attention has been focused on the molecular mechanisms and signaling pathways that may underlie $\beta$-cell glucotoxicity (Poitout \& Robertson 2008, Weir et al. 2009, Bensellam et al. 2012), but they

Published by Bioscientifica Ltd. 
remain poorly understood. Endoplasmic reticulum (ER) stress has emerged over the last few years as an important mechanism of $\beta$-cell failure (Laybutt et al. 2007b, Eizirik et al. 2008, Scheuner \& Kaufman 2008, Back \& Kaufman 2012, Marhfour et al. 2012, Negi et al. 2012).

With their heavy engagement in protein synthesis and secretory activity, $\beta$-cells are particularly sensitive to disruption of ER function and accumulation of misfolded proteins. ER stress activates an adaptive mechanism termed the unfolded protein response (UPR). The adaptive UPR is aimed to alleviate ER stress through the upregulation of ER chaperones and folding enzymes (Eizirik et al. 2008, Scheuner \& Kaufman 2008, Back \& Kaufman 2012). Recent studies suggest that the regulation of adaptive UPR gene expression may play an important role in the $\beta$-cell response to environmental challenge induced by obesity; although upregulation of adaptive UPR gene expression characterizes $\beta$-cell compensation and protection from diabetes, a decline in the adaptive UPR is associated with $\beta$-cell failure and progression to diabetes (Quan et al. 2012, Chan et al. 2013). Therefore, knowledge about the factors that regulate adaptive UPR gene expression in islets is critically important to understand the mechanisms responsible for the switch from $\beta$-cell compensation to failure in diabetes.

While the complex effects of acute/short-term high glucose on the UPR have been previously described (Wang et al. 2005, Lipson et al. 2006, Elouil et al. 2007, Seo et al. 2008, Zhang et al. 2009, Bensellam et al. 2012, Tang et al. 2012), the effects of continuous long-term exposure of $\beta$-cells to hyperglycemia remain to be clarified. In this study, we used a transplantation model to examine the effects of in vivo chronic hyperglycemia on UPR gene expression and $\beta$-cell differentiation in transplanted mouse islets.

\section{Materials and methods}

\section{Mice and islet transplantation}

C57BL/6 mice were supplied by the Garvan Institute breeding facility and were used both as islet donors and recipients. Animals were kept under conventional conditions with free access to food and water. Procedures were approved by the Garvan Institute, St Vincent's Hospital Animal Experimentation Ethics Committee following the guidelines issued by the National Health and Medical Research Council of Australia. Graft recipients were either normal or diabetic mice. Mice were rendered diabetic by a single i.p. dose of streptozotocin $(180 \mathrm{mg} / \mathrm{kg}$ body weight, dissolved in citrate buffer; Sigma). Blood samples were taken via tail prick for measurement of glucose levels (AccuChek glucose monitor; Roche Diagnostics). To assess the effects of continuous exposure to diabetes on gene expression in transplanted islets, diabetic mice were transplanted under the kidney capsule with islets isolated from one donor mouse per recipient - an insufficient number to reverse hyperglycemia (diabetic group). To assess the effects of reversing hyperglycemia after islet transplantation, diabetic mice were transplanted under the kidney capsule with islets isolated from three donor mice per recipient - a sufficient number to reverse hyperglycemia (diabetic-normalized group). Control nondiabetic mice were transplanted under the kidney capsule with islets isolated from either one or three donor mice per recipient. Islet transplantation was performed as described previously (Walters et al. 2009). Mice were bled for measurement of glucose levels in the fed state on days $0,1,3,7,10,15,17$, and 21 . Twenty-one days after transplantation, islet grafts were excised and RT-PCR was used to assess gene expression. To assess possible contamination of the grafts with renal parenchymal tissue, expression of the kidney-specific organic anion transporter, solute carrier family 22 (organic anion transporter), member 6 (slc22a6) (Lopez-Nieto et al. 1997), was measured.

\section{RNA analysis}

Total RNA was extracted using RNeasy Mini Kit (Qiagen) and cDNA was synthesized using the QuantiTect RT Kit (Qiagen). Real-time PCR was performed using Power SYBR Green PCR Master Mix (Applied Biosystems) on a 7900HT Real-Time PCR System (Applied Biosystems). Primer sequences are provided in Table 1 . The value obtained for each specific product was normalized to a control gene (cyclophilin A; Kjorholt et al. 2005) and expressed as a fold change of the value in islet grafts from control nondiabetic mice transplanted with islets isolated from one donor mouse per recipient.

\section{Xbp1 splicing}

Total RNA was extracted from islets and reverse transcribed as described earlier. Xbp1 cDNA was amplified by PCR and digested with Pst 1 that cuts unprocessed $X b p 1$ cDNA into fragments (Calfon et al. 2002). Processed (activated) Xbp 1 cDNA lacks the restriction site and remains intact. Processed (intact) and unprocessed (cut) $X b p 1$ were quantified by densitometry. The value obtained for processed $X b p 1$ was expressed as a ratio of the total (processed+unprocessed) Xbp1 mRNA levels for each

Published by Bioscientifica Ltd. 
Table 1 Sequences of oligonucleotide primers. Aliases of gene symbols given in parentheses

\begin{tabular}{l} 
Gene symbols \\
\hline Atf4 \\
Bak1 \\
Bax \\
Beta2 (Neurod1) \\
BiP (Hspa5, Grp78) \\
Catalase \\
Chop (Ddit3, Gadd153) \\
Cyclophilin A \\
Dnajb9 \\
Erp72 (Pdia4) \\
Fkbp11 \\
Gck \\
Glp1r \\
Glut2 (SIc2a2) \\
Gpr40 (Ffar1) \\
Gpx (Gpx1, CGpx) \\
Grp94 (Hsp90b1) \\
HO-1 (Hmox1, Hsp32) \\
II1 \\
Kir6.2 (Kcnj11) \\
Mafa \\
mGPDH (Gpd2) \\
Nkx6.1 \\
Orp150 (Hyou1) \\
Pc (Pcx) \\
Pdx1 \\
Serca2b (Atp2a2) \\
Slc22a6 (NKT) \\
Tnfo \\
Trib3 \\
Xbp1 \\
Xbp1s-Xbp1 splicing \\
\end{tabular}

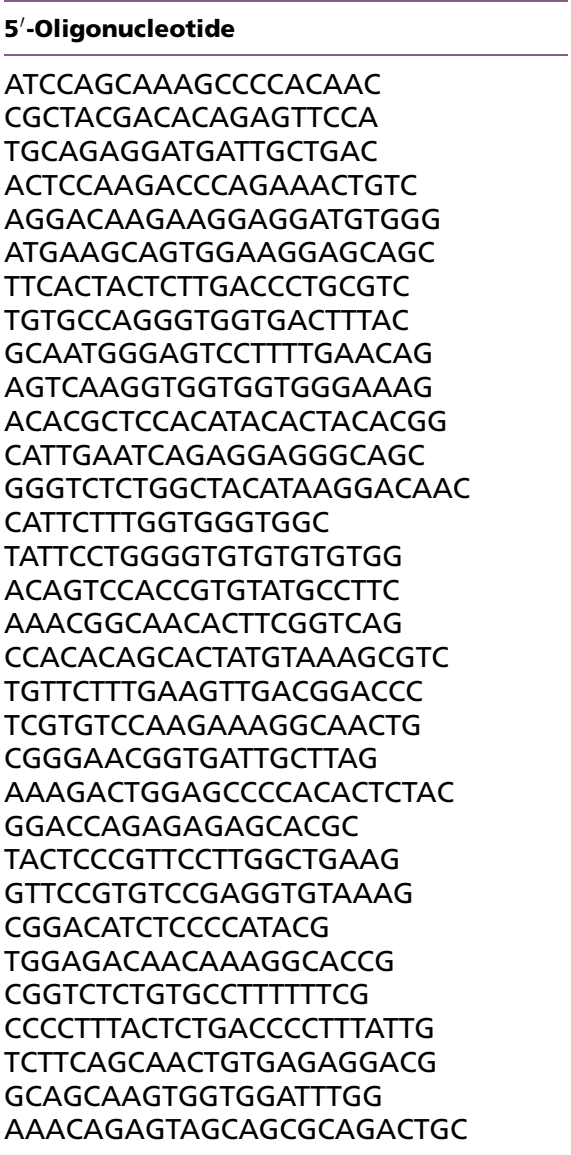

\begin{tabular}{l} 
3'-oligonucleotide \\
\hline CAAGCCATCATCCATAGCCG \\
GGTAGACGTACAGGGCCAGA \\
GATCAGCTCGGGCACTTTAG \\
ACTGGTAGGAGTAGGGATGCAC \\
ACCGAAGGGTCATTCCAAGTG \\
CTGTCAAAGTGTGCCATCTCGTC \\
CACTGACCACTCTGTTTCCGTTTC \\
TGGGAACCGTTTGTGTTTGG \\
TCCTGGAAGTGATGCCTTTGTC \\
TGGGAGCAAAATAGATGGTAGGG \\
ATGACTGCTCTTCGCTTCTCTCCC \\
TAGTGGACTGGGAGCATTTGTGGG \\
AAGGATGGCTGAAGCGATGAC \\
CCTGAGTGTGTTTGGAGCG \\
CCAAGGGCAGAAAGAAGAGCAG \\
CTCTTCATTCTTGCCATTCTCCTG \\
GCATCCATCTCTTCTCCCTCATC \\
GTTCGGGAAGGTAAAAAAAGCC \\
CCACAGCCACAATGAGTGATACTG \\
GGAAGGCAGATGAAAAGGAGTGG \\
GGAGGTTGGGACGCAGAA \\
ATCCCGTATTTCACCTCTGCTTC \\
TTCGGGTCCAGAGGTTTG \\
GGCTGTGGCAGTGTTGTCATTG \\
CGCAGAAGGATGTCCCTGAAAC \\
AAAGGGAGCTGGACGCGG \\
CAGAGCAGGAGCATCATTCACAC \\
TAGCCCCTCTTCTTGTTTCCC \\
AACCTGACCACTCTCCCTTTGC \\
TCCAGACATCAGCCGCTTTG \\
AGATGTTCTGGGGAGGTGACAAC \\
GGATCTCTAAAACTAGAGGCTTGGTG
\end{tabular}

sample. These ratios are expressed as fold change of the ratio in islet grafts from control nondiabetic mice transplanted with islets isolated from one donor mouse per recipient.

\section{Statistical analysis}

All results are presented as means \pm s.E.M. Statistical analyses were performed using Student's $t$-test or ANOVA.

\section{Results}

\section{Changes in blood glucose levels after islet transplantation}

The time-course changes in blood glucose levels after islet transplantation are shown in Fig. 1. Hyperglycemia was apparent in streptozotocin-treated mice on the day of transplantation. In diabetic mice transplanted with islets isolated from three donor mice, blood glucose concentrations fell to normal levels within 3 days (Fig. 1).
By contrast, in diabetic mice transplanted with islets isolated from one donor mouse, blood glucose levels remained significantly elevated throughout the time course (Fig. 1). Blood glucose levels after 3 days averaged 6.7 and $6.9 \mathrm{mmol} / \mathrm{l}$ in control mice transplanted with islets from one or three donors and 11.8 and $5.8 \mathrm{mmol} / \mathrm{l}$ in streptozotocin-treated mice transplanted with islets from one or three donors $(P<0.001)$.

\section{Changes in UPR gene expression in islet grafts}

Twenty-one days after transplantation, mRNA levels were analyzed in islet grafts retrieved from control (islets from one or three donors), diabetic (islets from one donor), and diabetic-normalized (islets from three donors) mice. Expression levels in islet grafts from control mice with islets from one or three donors were similar. In comparison with control mice (islets from one donor), islet grafts from diabetic mice exhibited markedly reduced mRNA levels of many UPR genes important for adaptation to ER stress (Fig. 2A). The mRNA levels of ER-resident

Published by Bioscientifica Ltd. 


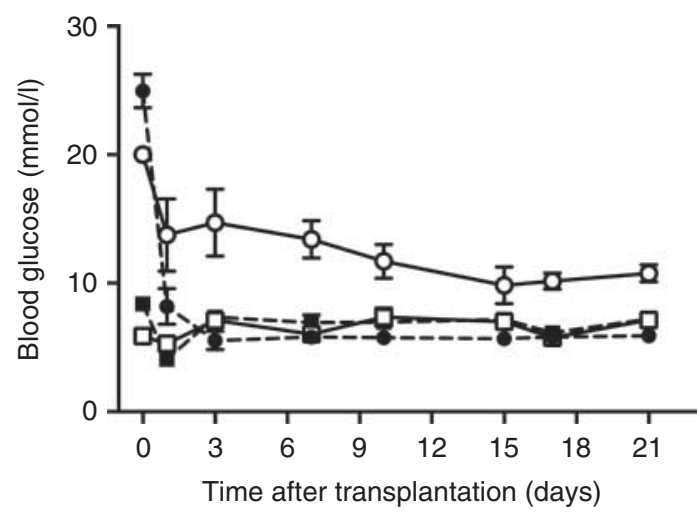

Figure 1

Time-course changes in blood glucose levels in the fed state after islet transplantation. Control nondiabetic mice were transplanted with islets isolated from one ( $n=5$, open squares, solid line) or three $(n=5$, closed squares, dashed line) donor mice per recipient. Diabetic mice were transplanted with islets isolated from one ( $n=5$, open circles, solid line) or three ( $n=5$, closed circles, dashed line) donor mice per recipient. Blood glucose levels were measured on days $0,1,3,7,10,15,17$, and 21 after transplantation. All results are mean \pm s.E.M.; ANOVA, $P<0.001$; blood glucose levels in diabetic mice transplanted with islets isolated from one donor.

chaperones (BiP (Hspa5), Grp94 (Hsp90b1), and Orp150 (Hyou1)) and protein foldases (Dnajb9, Erp72 (Pdia4), and Fkbp11) were reduced by $30-60 \%$ in islet grafts from diabetic mice compared with control mice. Strikingly, the normalization of blood glucose levels completely restored the abundance of adaptive UPR genes to the expression levels apparent in control islet grafts (Fig. 2A), suggesting that chronic hyperglycemia clearly contributes to the downregulation of adaptive UPR gene expression in transplanted islets. The expression levels of many adaptive UPR genes are regulated by the transcription factors Atf6 (Adachi et al. 2008, Teodoro et al. 2012) and IRE1-activated Xbp1 (Lee et al. 2003, Yoshida et al. 2003). In concert with the changes in adaptive UPR gene expression, Xbp1 mRNA levels were markedly reduced in islet grafts from diabetic mice and partially restored in grafts from diabeticnormalized mice (Fig. 2B). However, Xbp1 splicing (activation) was similarly reduced in grafts from diabetic and diabetic-normalized mice (Fig. 2B).

We tested expression of genes activated downstream of the PERK arm of the UPR. Activation of PERK and the transcription factor, Atf4, leads to upregulation of proapoptotic genes Chop (Ddit3) and Trib3. The mRNA levels of Atf4, Chop, and Trib3 were reduced by $40-65 \%$ in islet grafts from diabetic mice compared with control mice (Fig. 2B). These changes were at least partially restored in islet grafts from diabetic-normalized mice (Fig. 2B).
Thus, the data demonstrate for the first time that continuous exposure to chronic hyperglycemia downregulates steady state mRNA levels of genes regulated by multiple arms of the UPR in transplanted islets. This response encompasses both adaptive and pro-apoptotic UPR gene expression.

\section{Changes in islet-associated transcription factor and $\beta$-cell function genes in islet grafts}

We tested whether the changes in UPR gene expression were associated with an altered pattern of $\beta$-cell differentiation in transplanted islets. In islet grafts from diabetic mice, mRNA levels of several transcription factors important for the maintenance of the $\beta$-cell differentiation (Pdx1, Beta2 (Neurod1), Nkx6.1 (Nkx6-1), and Mafa) were reduced by $75-90 \%$ compared with those in control mice (Fig. 3A). This was accompanied by reduced expression of genes involved in $\beta$-cell glucose metabolism (glucose transporter 2 (Glut2 (Slc2a2)); the enzyme responsible for the majority of $\beta$-cell glucose phosphorylation, glucokinase $(G c k)$; the anaplerotic enzyme, pyruvate carboxylase $(P c(P c x))$; and the rate-limiting
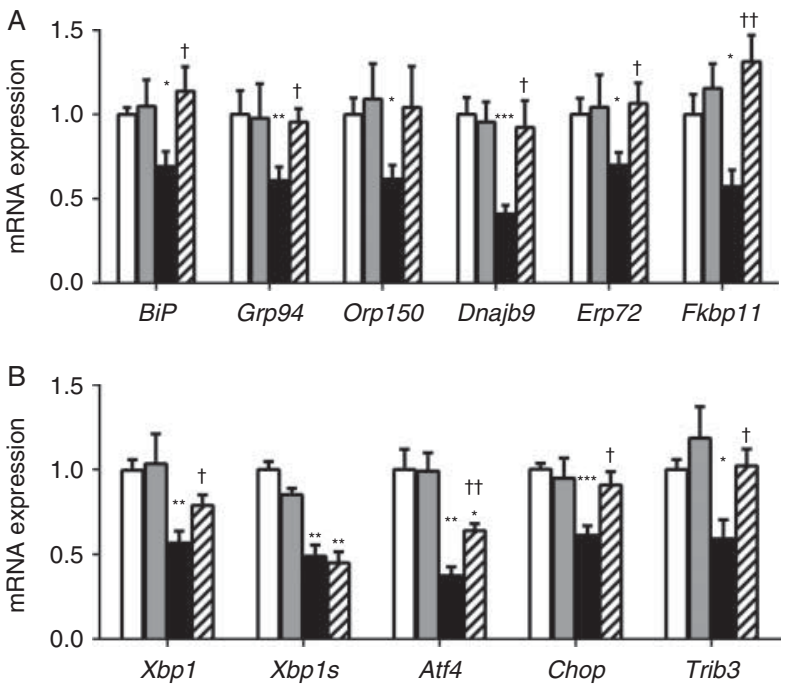

Figure 2

Changes in mRNA expression of UPR genes in transplanted islets. Total RNA was extracted, reverse transcribed, and analyzed by real-time RT-PCR. Xbp 1 splicing was assessed as described previously (Akerfeldt et al. 2008). mRNA levels were determined in islet grafts from control mice (transplanted with islets from one (white bars) or three (gray bars) donors), diabetic mice (black bars), and diabetic-normalized mice (striped bars). mRNA levels were expressed as fold change of the levels in islet grafts from control mice (transplanted with islets from one donor). $n=4-5$ in each group. All results are mean \pm s.E.M.; $* P<0.05, * * P<0.01$, and $* * * P<0.001$ vs islet grafts from control mice (transplanted with islets from one donor) for each gene. ${ }^{\dagger} P<0.05,{ }^{\dagger \dagger} P<0.01$ represents islet grafts from diabetic-normalized vs diabetic mice for each gene.

Published by Bioscientifica Ltd. 

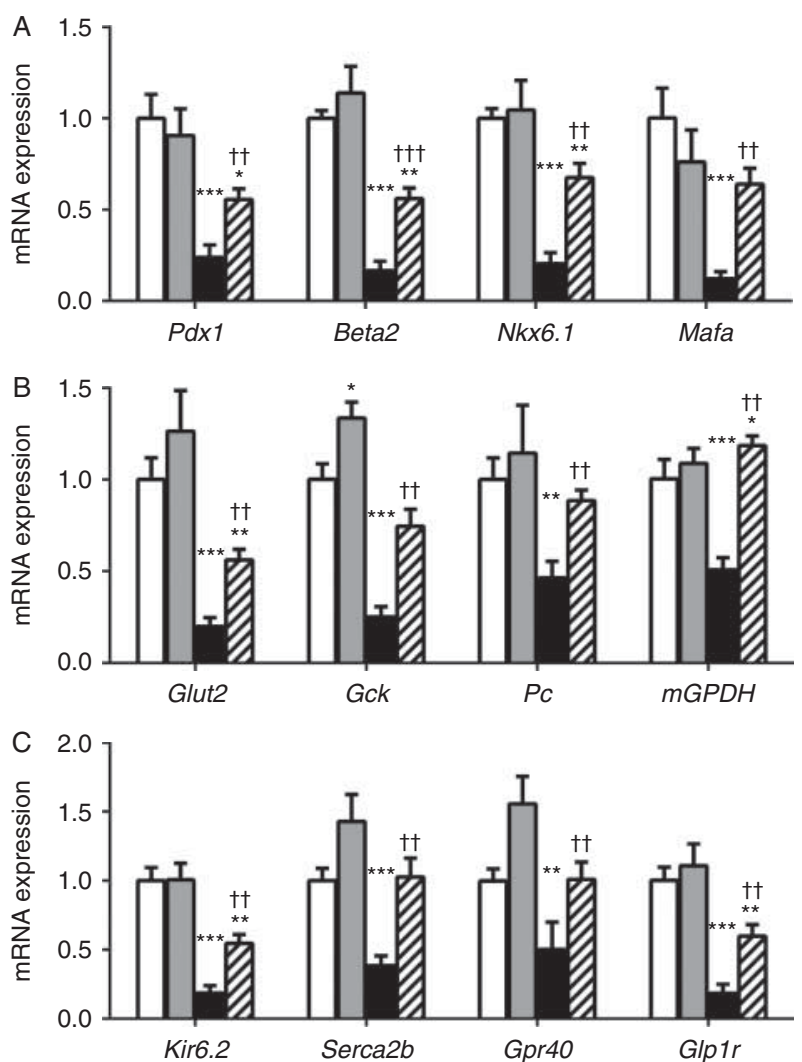

Figure 3

Changes in mRNA expression of islet-associated transcription factors and genes that optimize $\beta$-cell function in transplanted islets. Total RNA was extracted, reverse transcribed, and analyzed by real-time RT-PCR. mRNA levels were determined in islet grafts from control mice (transplanted with islets from one (white bars) or three (gray bars) donors), diabetic mice (black bars), and diabetic-normalized mice (striped bars). mRNA levels were expressed as fold change of the levels in islet grafts from control mice (transplanted with islets from one donor). $n=4-5$ in each group. All results are mean \pm s.E.M.; $* P<0.05$, $* * P<0.01$, and $* * * P<0.001$ vs islet grafts from control mice (transplanted with islets from one donor) for each gene.

${ }^{+\dagger} P<0.01$ and ${ }^{+t+} P<0.001$ represents islet grafts from diabetic-normalized vs diabetic mice for each gene.

enzyme of the glycerol phosphate shuttle, mitochondrial glycerol phosphate dehydrogenase ( $m G P D H(G p d 2)$ ); Fig. 3B), ion channels important for the stimulation of insulin secretion (the pore-forming subunit of the ATPsensitive $\mathrm{K}^{+}$channel (Kir6.2 (Kcnj11)) and a sarco/ER Ca ${ }^{2+}$. ATPase pump (Serca2b (Atp2a2)); Fig. 3C), the free fatty acid receptor, G-protein-coupled receptor 40 (Gpr40 (Ffar1)), and the incretin GLP-1 receptor (Glp1r) (Fig. 3C). Expression of all the tested $\beta$-cell differentiation genes was at least partially restored in islet grafts from diabetic-normalized mice (Fig. 3). These data suggest a convergence in the regulation of UPR and $\beta$-cell differentiation gene expression by hyperglycemia in transplanted islets.

\section{Changes in antioxidant and pro-inflammatory cytokine mRNA in islet grafts}

Oxidative stress and inflammation have been implicated in $\beta$-cell failure in diabetes (Laybutt et al. 2002, Poitout \& Robertson 2008, Donath \& Shoelson 2011, Gregor \& Hotamisligil 2011). The mRNA levels of oxidative stressinducible genes, heme oxygenase-1 (HO-1 (Hmox1)), glutathione peroxidase $(G p x(G p x 1))$, and catalase (Cat) (Fig. 4A), and the pro-inflammatory cytokines, Il1 $\beta$ (Il1b) and Tnf $\alpha$ (Tnf) (Fig. 4B), were upregulated in islet grafts from diabetic mice. However, the increased mRNA levels were not affected by the lowering of hyperglycemia in diabetic-normalized mice (Fig. 4A and B), suggesting that the upregulation of antioxidant and cytokine expression is independent of glycemia in transplanted islets. Moreover, expression levels of pro-apoptosis genes, Bak1 and Bax, were unchanged in islet grafts from diabetic mice compared with control mice (Fig. 4B).

The results of this study were not due to variable contamination with kidney tissue in the excised grafts. mRNA levels of the kidney-specific marker, Slc22a6, were low compared with those in kidney and not significantly
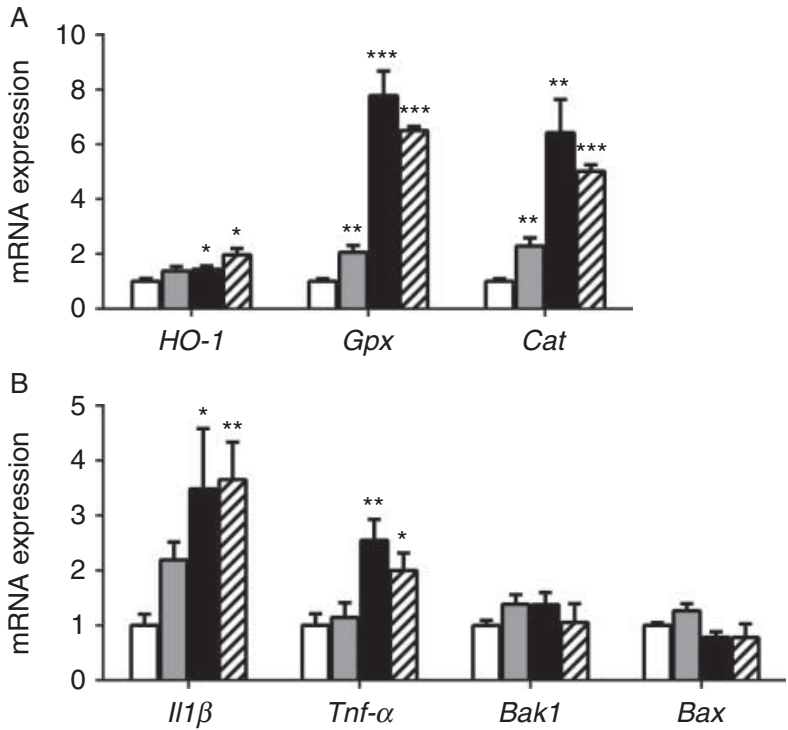

Figure 4

Changes in mRNA expression of antioxidant and inflammation genes in transplanted islets. Total RNA was extracted, reverse transcribed, and analyzed by real-time RT-PCR. mRNA levels were determined in islet grafts from control mice (transplanted with islets from one (white bars) or three (gray bars) donors), diabetic mice (black bars), and diabetic-normalized mice (striped bars). mRNA levels were expressed as fold change of the levels in islet grafts from control mice (transplanted with islets from one donor). $n=4-5$ in each group. All results are mean \pm s.E.M.; $* P<0.05, * * P<0.01$, and $* * * P<0.001$ vs islet grafts from control mice (transplanted with islets from one donor) for each gene.

Published by Bioscientifica Ltd. 
different among the groups $(6.3 \pm 1.8,7.8 \pm 2.9,11.6 \pm 3.8$, and $9.7 \pm 2.3 \%$ of kidney in islet grafts from control (islets from one or three donors), diabetic, and diabetic-normalized mice respectively).

\section{Discussion}

The maintenance of an intact adaptive UPR is essential for prevention of $\beta$-cell failure (Eizirik et al. 2008, Scheuner \& Kaufman 2008, Back \& Kaufman 2012). Using a transplantation model, we show that chronic exposure of $\beta$-cells to diabetes leads to downregulation of multiple arms of UPR gene expression. We also observed partial to complete recovery of UPR gene expression in grafts from mice with normalized glycemia, suggesting that the severe deterioration was associated with continuous exposure to diabetes. A striking correlation was identified between downregulation of UPR gene expression and the loss of $\beta$-cell differentiation in islet grafts exposed to continuous hyperglycemia. Importantly, these gene expression changes can be further correlated with a loss of glucose-induced insulin secretion from the graft-bearing kidney (Korsgren et al. 1990, Ogawa et al. 1995). The deleterious influence of chronic hyperglycemia on adaptive UPR gene expression may contribute to the failure of $\beta$-cells and transplanted islets to maintain adequate insulin secretion in diabetes.

Our study provides the first demonstration that in vivo chronic hyperglycemia strongly reduces genes of the IRE1/ATF6 and PERK/eIF2 $\alpha$ pathways, which encompass both adaptive and pro-apoptotic UPR gene expressions. By contrast, acute high-glucose treatment of $\beta$-cells in vitro stimulates IRE1-mediated UPR gene expression that is thought to enhance insulin biosynthesis (Lipson et al. 2006, Elouil et al. 2007), while exerting complex effects on the PERK/eIF2 $\alpha$ pathway that are mainly inhibitory (Elouil et al. 2007, Vander Mierde et al. 2007). With treatment periods of $24-96 \mathrm{~h}$, UPR activation is thought to contribute to hyperglycemia-mediated inhibition of insulin synthesis and secretion in vitro (Seo et al. 2008, Zhang et al. 2009) and in vivo (Tang et al. 2012). In the longer term, upregulation of protective UPR genes of the IRE1 pathway is associated with the mild hyperglycemia imposed on human islets transplanted into mouse recipients, which have slightly higher blood glucose levels than humans (Kennedy et al. 2010). However, in type 2 diabetes, CHOP protein levels are increased and may contribute to $\beta$-cell apoptosis (Akerfeldt et al. 2008, Cunha et al. 2008, Song et al. 2008), suggesting failure of the adaptive UPR. We recently demonstrated that failure of the adaptive UPR was associated with $\beta$-cell dysfunction and progression to diabetes in obese $d b / d b$ mice (Chan et al. 2013). The influence of chronically elevated blood glucose to lower adaptive UPR gene expression may, in the setting of obesity, render $\beta$-cells susceptible to persistent or amplified ER stress induced by worsening hyperglycemia or additional factors such as hyperlipidemia, reactive oxygen species, hypoxia, inflammation, or enhanced insulin demand.

A strong correlation is emerging between the status of the adaptive UPR and $\beta$-cell differentiation. The results of this study demonstrate that the loss of UPR gene expression with diabetes and its partial recovery with diabetes normalization parallels the changes in $\beta$-cell differentiation. Convergent regulation is also displayed with acute high-glucose exposure, which promotes both adaptive UPR gene expression and the $\beta$-cell phenotype (Lipson et al. 2006, Elouil et al. 2007, Bensellam et al. 2012). Furthermore, several molecular links have been identified in which islet-associated transcription factors regulate genes involved in ER function, and ER stressinducible transcription factors regulate genes implicated in $\beta$-cell function (Lipson et al. 2006, Seo et al. 2008, Sachdeva et al. 2009, Allagnat et al. 2010). We propose that the loss of UPR gene expression under conditions of chronic hyperglycemia may be an integral part of the $\beta$-cell dedifferentiation process. In diabetes and with islet transplantation, this process may be an important mechanism that, in effect, trades function for survival under stress conditions. Chronic hyperglycemia leads to downregulation of insulin biosynthesis in transplanted islets (Laybutt et al. 2007a). The downregulation of ER-resident chaperones and protein foldases under diabetic conditions may occur as a consequence of reduced insulin synthesis activity. Glucotoxicity also leads to other stresses of the graft environment, such as oxidative stress, inflammation, impaired vascularization, and hypoxia, which may influence outcomes. Moreover, the possibility that hormones secreted by threefold more islets influence the restoration of islet graft gene expression in diabetic-normalized mice has not been excluded.

In conclusion, our study demonstrates for the first time the remarkable similarity in the altered patterns of UPR and $\beta$-cell differentiation gene expression in transplanted islets. Importantly, our study shows that chronic hyperglycemia contributes to downregulation of adaptive UPR gene expression, thus suggesting a new mechanism of $\beta$-cell glucotoxicity. The loss of adaptive UPR gene expression may be a major factor, combined with $\beta$-cell dedifferentiation, in the impaired insulin secretion that accompanies poor transplant outcomes and progressive

Published by Bioscientifica Ltd. 
$\beta$-cell failure in diabetes. Thus, our study provides new insight into the molecular mechanisms by which persistent hyperglycemia produces the toxic spiral of insulin secretory dysfunction and $\beta$-cell demise.

\section{Declaration of interest}

The authors declare that there is no conflict of interest that could be perceived as prejudicing the impartiality of the research reported.

\section{Funding}

This work was supported by grants from the Juvenile Diabetes Research Foundation (JDRF) and the National Health and Medical Research Council (NHMRC) of Australia. S T G is supported by an Australian Research Council Future Fellowship and an NHMRC Senior Research Fellowship. D R L is supported by an Australian Research Council Future Fellowship.

\section{Author contribution statement}

S N W and $J$ L designed and performed studies and critically reviewed the manuscript. J Y C analyzed data and critically reviewed the manuscript. S T G conceived and designed the studies, analyzed data, and critically reviewed the manuscript. $D \mathrm{R} L$ conceived and designed the studies, analyzed data, and wrote the manuscript. S T G and D R L contributed equally to this paper and share senior authorship.

\section{Acknowledgements}

The authors thank Mohammed Bensellam and Trevor Biden for critical review of the manuscript.

\section{References}

Adachi Y, Yamamoto K, Okada T, Yoshida H, Harada A \& Mori K 2008 ATF6 is a transcription factor specializing in the regulation of quality control proteins in the endoplasmic reticulum. Cell Structure and Function 33 75-89. (doi:10.1247/csf.07044)

Akerfeldt MC, Howes J, Chan JY, Stevens VA, Boubenna N, McGuire HM, King C, Biden TJ \& Laybutt DR 2008 Cytokine-induced $\beta$-cell death is independent of endoplasmic reticulum stress signaling. Diabetes $\mathbf{5 7}$ 3034-3044. (doi:10.2337/db07-1802)

Allagnat F, Christulia F, Ortis F, Pirot P, Lortz S, Lenzen S, Eizirik DL \& Cardozo AK 2010 Sustained production of spliced X-box binding protein 1 (XBP1) induces pancreatic $\beta$ cell dysfunction and apoptosis. Diabetologia 53 1120-1130. (doi:10.1007/s00125-010-1699-7)

Back SH \& Kaufman RJ 2012 Endoplasmic reticulum stress and type 2 diabetes. Annual Review of Biochemistry 81 767-793. (doi:10.1146/ annurev-biochem-072909-095555)

Bensellam M, Laybutt DR \& Jonas JC 2012 The molecular mechanisms of pancreatic $\beta$-cell glucotoxicity: recent findings and future research directions. Molecular and Cellular Endocrinology 364 1-27. (doi:10.1016/ j.mce.2012.08.003)

Calfon M, Zeng H, Urano F, Till JH, Hubbard SR, Harding HP, Clark SG \& Ron D 2002 IRE1 couples endoplasmic reticulum load to secretory capacity by processing the XBP-1 mRNA. Nature 415 92-96. (doi:10.1038/415092a)

Chan JY, Luzuriaga J, Bensellam M, Biden TJ \& Laybutt DR 2013 Failure of the adaptive unfolded protein response in islets of obese mice is linked with abnormalities in $\beta$-cell gene expression and progression to diabetes. Diabetes 62 1557-1568. (doi:10.2337/db12-0701)

Cunha DA, Hekerman P, Ladriere L, Bazarra-Castro A, Ortis F, Wakeham MC, Moore F, Rasschaert J, Cardozo AK, Bellomo E et al. 2008 Initiation and execution of lipotoxic ER stress in pancreatic $\beta$-cells. Journal of Cell Science 121 2308-2318. (doi:10.1242/jcs.026062)

Donath MY \& Shoelson SE 2011 Type 2 diabetes as an inflammatory disease. Nature Reviews. Immunology 11 98-107. (doi:10.1038/nri2925)

Eizirik DL, Cardozo AK \& Cnop M 2008 The role for endoplasmic reticulum stress in diabetes mellitus. Endocrine Reviews 29 42-61. (doi:10.1210/er. 2007-0015)

Elouil H, Bensellam M, Guiot Y, Vander Mierde D, Pascal SM, Schuit FC \& Jonas JC 2007 Acute nutrient regulation of the unfolded protein response and integrated stress response in cultured rat pancreatic islets. Diabetologia 50 1442-1452. (doi:10.1007/s00125-007-0674-4)

Gregor MF \& Hotamisligil GS 2011 Inflammatory mechanisms in obesity. Annual Review of Immunology 29 415-445. (doi:10.1146/annurevimmunol-031210-101322)

Kennedy J, Katsuta H, Jung MH, Marselli L, Goldfine AB, Balis UJ, Sgroi D, Bonner-Weir S \& Weir GC 2010 Protective unfolded protein response in human pancreatic $\beta$ cells transplanted into mice. PLoS ONE 5 e11211. (doi:10.1371/journal.pone.0011211)

Kjorholt C, Akerfeldt MC, Biden TJ \& Laybutt DR 2005 Chronic hyperglycemia, independent of plasma lipid levels, is sufficient for the loss of $\beta$-cell differentiation and secretory function in the $\mathrm{db} / \mathrm{db}$ mouse model of diabetes. Diabetes 54 2755-2763. (doi:10.2337/diabetes.54.9. 2755)

Korsgren O, Jansson L, Sandler S \& Andersson A 1990 Hyperglycemiainduced B cell toxicity. The fate of pancreatic islets transplanted into diabetic mice is dependent on their genetic background. Journal of Clinical Investigation 86 2161-2168. (doi:10.1172/JCI114955)

Laybutt DR, Hawkins YC, Lock J, Lebet J, Sharma A, Bonner-Weir S \& Weir GC $2007 a$ Influence of diabetes on the loss of $\beta$ cell differentiation after islet transplantation in rats. Diabetologia 50 2117-2125. (doi:10.1007/s00125007-0749-2)

Laybutt DR, Preston AM, Akerfeldt MC, Kench JG, Busch AK, Biankin AV \& Biden TJ $2007 b$ Endoplasmic reticulum stress contributes to $\beta$ cell apoptosis in type 2 diabetes. Diabetologia 50 752-763. (doi:10.1007/ s00125-006-0590-z)

Laybutt DR, Kaneto H, Hasenkamp W, Grey S, Jonas JC, Sgroi DC, Groff A, Ferran C, Bonner-Weir S, Sharma A et al. 2002 Increased expression of antioxidant and antiapoptotic genes in islets that may contribute to $\beta$-cell survival during chronic hyperglycemia. Diabetes $51413-423$. (doi:10.2337/diabetes.51.2.413)

Lee AH, Iwakoshi NN \& Glimcher LH 2003 XBP-1 regulates a subset of endoplasmic reticulum resident chaperone genes in the unfolded protein response. Molecular and Cellular Biology 23 7448-7459. (doi:10.1128/MCB.23.21.7448-7459.2003)

Lipson KL, Fonseca SG, Ishigaki S, Nguyen LX, Foss E, Bortell R, Rossini AA \& Urano F 2006 Regulation of insulin biosynthesis in pancreatic $\beta$ cells by an endoplasmic reticulum-resident protein kinase IRE1. Cell Metabolism 4 245-254. (doi:10.1016/j.cmet.2006.07.007)

Lopez-Nieto CE, You G, Bush KT, Barros EJ, Beier DR \& Nigam SK 1997 Molecular cloning and characterization of NKT, a gene product related to the organic cation transporter family that is almost exclusively expressed in the kidney. Journal of Biological Chemistry 272 6471-6478. (doi:10.1074/jbc.272.10.6471)

Marhfour I, Lopez XM, Lefkaditis D, Salmon I, Allagnat F, Richardson SJ, Morgan NG \& Eizirik DL 2012 Expression of endoplasmic reticulum stress markers in the islets of patients with type 1 diabetes. Diabetologia 55 2417-2420. (doi:10.1007/s00125-012-2604-3)

Negi S, Park SH, Jetha A, Aikin R, Tremblay M \& Paraskevas S 2012 Evidence of endoplasmic reticulum stress mediating cell death in transplanted human islets. Cell Transplantation 21 889-900. (doi:10.3727/ 096368911X603639) 
Ogawa Y, Noma Y, Davalli AM, Wu YJ, Thorens B, Bonner-Weir S \& Weir GC 1995 Loss of glucose-induced insulin secretion and GLUT2 expression in transplanted $\beta$-cells. Diabetes 44 75-79. (doi:10.2337/ diabetes.44.1.75)

Poitout V \& Robertson RP 2008 Glucolipotoxicity: fuel excess and $\beta$-cell dysfunction. Endocrine Reviews 29 351-366. (doi:10.1210/er.2007-0023)

Quan W, Hur KY, Lim Y, Oh SH, Lee JC, Kim KH, Kim GH, Kim SW, Kim HL, Lee MK et al. 2012 Autophagy deficiency in $\beta$ cells leads to compromised unfolded protein response and progression from obesity to diabetes in mice. Diabetologia 55 392-403. (doi:10.1007/s00125-0112350-y)

Sachdeva MM, Claiborn KC, Khoo C, Yang J, Groff DN, Mirmira RG \& Stoffers DA 2009 Pdx1 (MODY4) regulates pancreatic $\beta$ cell susceptibility to ER stress. PNAS 106 19090-19095. (doi:10.1073/pnas. 0904849106)

Scheuner D \& Kaufman RJ 2008 The unfolded protein response: a pathway that links insulin demand with $\beta$-cell failure and diabetes. Endocrine Reviews 29 317-333. (doi:10.1210/er.2007-0039)

Seo HY, Kim YD, Lee KM, Min AK, Kim MK, Kim HS, Won KC, Park JY, Lee KU, Choi HS et al. 2008 Endoplasmic reticulum stress-induced activation of activating transcription factor 6 decreases insulin gene expression via up-regulation of orphan nuclear receptor small heterodimer partner. Endocrinology 149 3832-3841. (doi:10.1210/en. 2008-0015)

Song B, Scheuner D, Ron D, Pennathur S \& Kaufman RJ 2008 Chop deletion reduces oxidative stress, improves $\beta$ cell function, and promotes cell survival in multiple mouse models of diabetes. Journal of Clinical Investigation 118 3378-3389. (doi:10.1172/JCI34587)

Tang C, Koulajian K, Schuiki I, Zhang L, Desai T, Ivovic A, Wang P, Robson-Doucette C, Wheeler MB, Minassian B et al. 2012 Glucose-induced $\beta$ cell dysfunction in vivo in rats: link between oxidative stress and endoplasmic reticulum stress. Diabetologia $\mathbf{5 5}$ 1366-1379. (doi:10.1007/s00125-012-2474-8)

Teodoro T, Odisho T, Sidorova E \& Volchuk A 2012 Pancreatic $\beta$-cells depend on basal expression of active ATF6 $\alpha$-p50 for cell survival even under nonstress conditions. American Journal of Physiology. Cell Physiology 302 C992-C1003. (doi:10.1152/ajpcell.00160.2011)

Vander Mierde D, Scheuner D, Quintens R, Patel R, Song B, Tsukamoto K, Beullens M, Kaufman RJ, Bollen M \& Schuit FC 2007 Glucose activates a protein phosphatase-1-mediated signaling pathway to enhance overall translation in pancreatic $\beta$-cells. Endocrinology 148 609-617. (doi:10.1210/en.2006-1012)

Walters S, Webster KE, Sutherland A, Gardam S, Groom J, Liuwantara D, Marino E, Thaxton J, Weinberg A, Mackay F et al. 2009 Increased CD4+ Foxp3 + T cells in BAFF-transgenic mice suppress T cell effector responses. Journal of Immunology 182 793-801.

Wang H, Kouri G \& Wollheim CB 2005 ER stress and SREBP-1 activation are implicated in $\beta$-cell glucolipotoxicity. Journal of Cell Science $\mathbf{1 1 8}$ 3905-3915. (doi:10.1242/jcs.02513)

Weir GC, Marselli L, Marchetti P, Katsuta H, Jung MH \& Bonner-Weir S 2009 Towards better understanding of the contributions of overwork and glucotoxicity to the $\beta$-cell inadequacy of type 2 diabetes. Diabetes, Obesity \& Metabolism 11 (Suppl 4) 82-90. (doi:10.1111/j.1463-1326. 2009.01113.x)

Yoshida H, Matsui T, Hosokawa N, Kaufman RJ, Nagata K \& Mori K 2003 A time-dependent phase shift in the mammalian unfolded protein response. Developmental Cell 4 265-271. (doi:10.1016/S15345807(03)00022-4)

Zhang L, Lai E, Teodoro T \& Volchuk A 2009 GRP78, but not proteindisulfide isomerase, partially reverses hyperglycemia-induced inhibition of insulin synthesis and secretion in pancreatic $\beta$-cells. Journal of Biological Chemistry 284 5289-5298. (doi:10.1074/jbc.M805477200)

Received in final form 18 June 2013

Accepted 5 July 2013

Accepted Preprint published online 5 July 2013
(C) 2013 Society for Endocrinology Printed in Great Britain 